\title{
32
}

\section{FREEING POLICY FROM THE PROXIMATE}

\section{Expanding the Scope of Public Health Practice to Match Epidemiological Insights}

\author{
DEVIN C. BOWLES
}

\section{Abstract}

Human health depends on the health of eco-planetary systems, many of which are under increasing anthropogenic pressure. In recent years, epidemiology has expanded its range of enquiry temporally and spatially, confirming many of these dependencies. Using climate change as a case study, I demonstrate that the capacity for public health action to mitigate the health effects of global ecological degradation has not kept pace.

There are several impediments to action. Diffuse responsibility impedes focusing efforts for change. Relatively slow mechanisms linking planetaryscale degradation with health impacts create an intergenerational conflict of interests. The momentum of both socio-economic and physical systems, such as the climate system, delays the feedback of consequences and hinders action. Over-determination of ecological pressure, in which multiple stressors could each individually degrade ecosystems, compounds the problem of diffuse responsibility and complicates resource allocation. The complexity of ecological degradation and constraints on effective solutions facilitate individual and societal self-deception, and thus corruption.

Despite these barriers, upstream intervention may be the only way to prevent the myriad ill effects of global environmental problems on human health. Epidemiologists should expand the scope of their power to impact the factors leading to global-scale ecological disruption. Several strategies are discussed. 


\section{Introduction}

Ecological systems necessary for human health are under increasing threat from diverse anthropogenic pressures. Threats of concern include biodiversity loss, disruptions to the nitrogen cycle and climate change, which has been labelled as the century's greatest health threat (Costello et al., 2009). As A. J. McMichael elucidates, a subset of epidemiologists is responding by expanding the spatial and temporal scope of their enquiry beyond proximate health risk factors to include population-level influences on health (McMichael, 1999). While only a minority of epidemiologists are directly involved, the discipline's overall understanding of the environmental and social systems that imbed health is increasing. Pathways from ecological disruption to ill health remain only partially described, but include undernutrition, poverty, limited access to ecosystem services, conflict over resources and decreased genetic diversity on which to base medical innovation. Negative consequences may be borne by all people, perhaps especially by those who contribute least to ecological disruption. While the spatial-temporal scope of epidemiological enquiry has expanded in line with humanity's pressure on the environment, the capacity for public health action lags.

Using climate change as a case study, I discuss barriers and enablers that affect public health issues mediated by global-scale environmental change. I suggest strategies by which epidemiology could help to meet the challenges posed by environmental degradation, including shifting the research and policy focus further upstream, altering the discipline's role in informing policy, in informing policy to better influence policy levers, and rethinking communication among professionals and with the public. Such strategies would contribute to a healthier planet, and, thereby, to healthier populations.

\section{Ecological Stress and Human Health}

There is an apparent paradox between the pattern of increasing health globally and the likelihood that health outcomes will stagnate or decline in future. However, both history and ecology are replete with examples of increased health and fertility being followed by substantial population contractions, in part from premature death, when the population surpasses the resource base (Diamond, 2005; Zhang et al., 2007, 2011). The disciplines of history and ecology are clear on these points, but their lessons have been missed by many people. Epidemiology and public health are in a unique position to highlight the current dangers precisely because of their recent successes. 
Humanity continues to increase pressure on the ecological systems that support human health. The Holocene, the period of environmental stability in which civilisation arose and prospered, has given way to the Anthropocene, the current period in which humans are the major force shaping Earth's ecology (Crutzen, 2002; Steffen et al., 2011). Nine interrelated ecological limits have been identified that could tip the planet from the stability characterising the Holocene and decrease its capacity to sustain humanity (Rockström et al., 2009).

Three safety thresholds have already been crossed, and this now could disrupt the worldwide ecological balance. Biodiversity loss may be occurring at a rate broadly comparable with the five previous mass extinctions, including that of the dinosaurs. If current losses continue, a sixth mass extinction event, in which the planet loses at least three-quarters of its species in a geologically short period, would occur (Barnosky et al., 2011). Agriculture and fertiliser production have substantially disrupted the nitrogen cycle, removing 35 million tonnes of N2 from the atmosphere annually for human use. Much of it flows into waterways, where it can disrupt ecology and lead to anoxic areas (Rockström et al., 2009). The concentrations of greenhouse gases are outside of humanity's safe operating space (Rockström et al., 2009), with deleterious effects on human health already evident (Epstein and Ferber, 2011; McMichael, 2012). While abundant human health requires functioning and robust ecosystems, anthropogenic pressure continues to expand.

\section{Impediments to Epidemiological Intervention}

A growing body of research exists on the 'knowledge-to-action gap' in health care, including the conversion of primary research into tools such as practice guidelines and the uptake of such tools by practitioners (Graham et al., 2006). Two-way interactions between research and practice are essential to facilitate practice that is based on the best available evidence and a research agenda influenced by practitioners to maximise utility and uptake (Graham et al., 2006). However, despite efforts to close the gap between research and practice, there remains a significant lag - estimated at up to 17 years - between knowledge production and mainstream practice in many areas of health care (Balas and Boren, 2000); furthermore, patients do not receive appropriate care at over two in five of their encounters with the American and Australian health systems (McGlynn et al., 2003; Runciman et al., 2012). This suggests that, true to the Greek roots of the word, epidemiology is better at the study of health than in the practice of improving it. 
The knowledge-to-action literature focuses largely on medical and paramedical practice, with less attention paid to other determinants of health, including ecological determinants (Graham et al., 2006). The task of bridging the knowledge-to-action gap for ecological health determinants possesses all of the challenges that it does for medical practice, and important additional challenges. Five characteristics make widespread ecological harm difficult to reverse. As discussed below, they also impede effective amelioration by epidemiologists: diffuse responsibility, intergenerational conflicting interests, momentum, overdetermination and corruption.

\section{Diffuse responsibility}

Responsibility for socio-economic drivers of ecological degradation is diffuse and spread over multiple levels of organisation. In the same way as responsibility for emerging medical epidemics such as diabetes and heart disease is dispersed across a wide range of actors, from individuals to organisations, regulators and politicians, so too does responsibility for ecological damage. As is the case for medical researchers attempting to use their findings to help reduce the prevalence of chronic disease, so must the epidemiologist attempting to preserve ecological health often contend with multiple sources of responsibility for degradation. Carbon dioxide, next to methane, is the main anthropogenic greenhouse gas and has numerous sources, including oil, coal and natural gas. These are consumed in myriad industries and across millions of sites daily.

Deforestation reduces the natural absorption of carbon dioxide, increasing its atmospheric concentration and further driving climate change. People who drive cars, use electricity generated at a coal-fired plant or who eat meat raised on feed farmed from the sites of clear-cut forests are also contributing to carbon dioxide emissions and thus bear some level of responsibility for current trends. At a higher level of organisation, those who structure incentives and subsidise energy in ways that encourage fossil fuel use are promoting consumption as a means of self-actualisation. They lobby governments against effective action on international treaties and deliberately disseminate misinformation about climate change. It is these entities that bear an even greater responsibility for contributing to climate change (Pearse, 2007; Hamilton, 2010). This trend may be exacerbated by the reliance on gross domestic product (GDP) as a measure of economic success, despite the fact that it was not designed to measure wellbeing (Kubiszewski et al., 2013). Diffuse responsibility impedes intervention because of the behaviour of so many people at different levels that would require change, and because unilateral strategies that target a single level or single aspects of the bigger issue (i.e. the types of strategies that are sufficiently straightforward as to be feasible) generally fail to establish sufficiently broad and sustainable change. 
Diffuse responsibility also leads to the tragedy of the commons, in which people overexploit common resources when benefits are individual but when costs are shared (Diamond, 2005). Put another way, the act of pollution is often facilitated because polluters do not bear the cost of negative externalities (Balmford et al., 2002). Theoretically at least, the tragedy of the commons could be averted if players would agree to a regulatory regime that aligned individual interests with common interests. To date, however, countries have failed to create an international regulatory system capable of averting climate change (Gardiner, 2006).

Problems associated with the tragedy of the commons are exacerbated by multiple levels of responsibility, each of which can claim that climate change is best solved by other levels. For example, an oil executive could argue that he or she is only satisfying consumer demand, while the driver of a fuel-inefficient vehicle can blame the manufacturer for his or her carbon dioxide emissions. The diffusion of responsibility complicates intervention by creating a situation of conflicting interests and ethical tension. Many of the worst effects of climate change, including on food production and reduced labour productivity, are in equatorial countries that have benefitted the least due to greenhouse gas emissions. Climate change will impact the health primarily of those who cannot afford to buffer themselves from it, by paying more for food when agricultural output falls (Cribb, 2010), or by buying an air conditioner to cope with heat stress. The ethical tension arises from the fact that the poor do not bear primary responsibility for climate change, which is the product of wealthy and middleclass lifestyles, yet they are suffering the harms from a changing climate.

\section{Intergenerational conflicting interests}

There is also a strong temporal conflict of interests (Gardiner, 2006). Carbon dioxide can persist in the atmosphere for centuries, where total concentrations depend on previous emissions. Changes to the climate from increased carbon dioxide can take years to unfold. Many of the effects of climate change similarly take time to manifest, including sea level rise from thermal expansion and melting glaciers. Those living a century hence will have to contend with a climate impacted by present-day emissions, even if humanity has stopped its carbon dioxide production completely by then (Friedlingstein et al., 2011). The current generation, thus, will not face the worst impacts of the climate it creates (Gardiner, 2006). This leads to a situation allied to the tragedy of the commons described above, except that intergenerational regulatory frameworks are impossible. Unborn generations are incapable of making or enforcing agreements with the present generation. Rational pursuit of narrowly defined, 'economically rational' self-interest is claimed by some to mean the current generation would emit without regard to future generations (Gardiner, 2006). 
The effects of many other forms of environmental destruction also take time to manifest, creating similar dynamics. Relevant phenomena that could disrupt civilisation include the accumulation of other persistent pollutants, resource depletion and disruption to elemental cycles such as nitrogen and phosphorus (Rockström et al., 2009).

\section{Momentum}

The term 'momentum' is often used to describe the lag between anthropogenic perturbations on the climate systems and the full effects of these perturbations. A similar lag exists in many socio-economic and political systems. Physical infrastructure associated with greenhouse gas emissions lasts for years, or decades. Incentives to utilise these 'investments' fully mean that they are unlikely to be decommissioned until it is considered economical to do so (i.e. by the measures of mainstream economics), regardless of their contribution to climate change. Coal-fuelled power plants built today may still be operational in 2050. The commitment for Los Angeles to become coal-free by 2025 offers some hope that this lag can be shortened, at least in some instances.

Elements of infrastructure are often interlinked with each other and with cultural norms, perpetuating existing infrastructure-cultural connections and hindering qualitative/substantive change. For example, high levels of automobile ownership, which represent substantial citizen investment, create a disincentive for governments to moderate road funding. Limited budgets mean that roads are built at the expense of other transportation infrastructure, increasing the incentive of citizens to continue to invest in cars. Cultural and emotional attachment to automobiles further impedes the rapid alteration of transport networks. Dependence on automobile infrastructure influences other aspects of development planning, increasing urban sprawl and dwelling size, and placing further pressure on the planet through ever-increasing contributions to climate change, resource depletion and air pollution.

\section{Over-determination}

Over-determination is a situation in which there are multiple causes which, individually, would result in a given outcome. Over-determined outcomes are thus difficult to change. When applied to ecological degradation, it requires distinct strategies to combat separate problems to preserve individual ecosystems or species. This complicates environmental resource allocation, especially in a context of limited government budgets. Over-determination compounds the problem of diffuse responsibility because one ecosystem can be under threat 
from multiple sources, each of which can blame others for any degradation that occurs. Over-determination impedes effective action while increasing the action required.

Ecosystems important to human health are under multiple threats. Ocean acidification, caused by the absorption of increasing levels of atmospheric carbon dioxide, is the twin of climate change. It interferes with the chemistry used by many marine organisms, including corals, to make their shells, and could eventually make shell production impossible. Ocean acidification, overfishing and pollution each pose existential threats to coral reefs (Bradbury, 2012). Bradbury argues that, together, they have created a situation in which 'there is no hope of saving the global coral reef ecosystem', though small pockets of functioning reef ecosystems may remain (Bradbury, 2012). Rising ocean temperatures that cause coral bleaching place additional stress on reef ecosystems. Reef ecosystems are an important food source for humanity and the primary source of protein for many in developing countries.

Other ecosystems important to human well-being are also under multiple threats. The Amazonian rainforest is shrinking from logging and land-use change, while altered precipitation patterns associated with climate change could lead to drought and enhance forest fire risk (Davidson et al., 2012). Even at the global level, humanity continues to promote several largely separate anthropogenic risks to the planet (Rockström et al., 2009).

\section{Corruption}

Diffuse responsibility, conflicts among intergenerational interests, momentum and over-determination all impede humanity's response to broad-scale environmental problems. Humanity lacks the conceptual tools to address effectively the ethical and practical issues that climate change raises (Gardiner, 2006). The complexity of problems and the practical constraints on effective solutions facilitate self-deception, at both the individual and the organisational level. Consequently, there is ample room for vested interests to manipulate the debate through a number of psychosocial mechanisms: pandering, hypocrisy, complacency, distraction, selective attention, unreasonable doubt and delusion. These mechanisms are also open to individuals for self-deception. The enhanced manipulation of others and self-deception leads to moral corruption by facilitating unethical behaviour (Gardiner, 2006, pp. 407-8). This is magnified in situations when action to preserve the environment is pitched against individual interests due to the tragedy of the commons. 


\section{Upstream Intervention}

The challenges of mitigating climate change and other global environmental problems are immense, yet upstream intervention may be the only way to prevent the resultant deterioration of human health. Climate change, like other large-scale ecological insults, will harm health through myriad pathways (Epstein and Ferber, 2011). According to one framework, primary effects will be those of the climate acting directly on human health, such as through increased rates of heatstroke (Butler and Harley, 2010). Secondary effects will operate via the web of life, such as changing ranges of mosquito-borne diseases. Tertiary effects are those which manifest through socio-economic and political pathways (Butler and Harley, 2010).

Climate change will change the distribution of many resources and likely diminish many renewable resources globally in the long term. This will combine with other factors to amplify food insecurity and malnourishment among many of the world's poor in the coming decades (Cribb, 2010).

Climate change is associated with conflict historically (Zhang et al., 2007, 2011), and increased resource conflict from climate change is predicted by the academy (Mazo, 2010; Hendrix and Salehyan, 2012; Bowles et al., 2014) and by the world's militaries (Sullivan et al., 2007; Morisetti, 2012). Climate change may also increase the risk of genocide. While individual causal pathways between climate change and ill health might be interrupted, their diversity and sheer number precludes comprehensive downstream health intervention. Upstream intervention that limits the rate and extent of climate change is required if all, or even most, of the health consequences of greenhouse gas emissions are to be averted.

\section{Power and Epidemiology}

Power relations are rarely examined in the medical knowledge-to-action gap literature (Graham et al., 2006). Yet, power relations are acknowledged as being of fundamental importance in the social sciences (Foucault, 1980; Comaroff and Comaroff, 1991), and become especially salient when actors are pursuing different and sometimes opposing goals. Maintaining and improving health is a primary goal of most actors within the health system. The goals of those with the greatest influence over ecological well-being, including multinational petroleum, mining, manufacturing and logging corporations, governments, advertisers and real estate developers, are more diverse, and health is often not among their priorities. Currently, epidemiologists can exert little power over these actors to ensure that their activities are consistent with current, let alone 
future, public health priorities. More insidiously, these actors cannot necessarily be relied on to influence the research agenda helpfully, to maximise its utility in achieving ecological or human health. Some may use their influence to bias the research agenda away from such questions in order to protect their own shortterm interests. To facilitate planetary and human health, epidemiologists must increase their influence over domains not traditionally associated with health.

\section{Overcoming Barriers}

Humanity is disrupting rapidly a number of global ecological processes necessary for the flourishing of, and even maintenance of, human health. The challenge is of a greater scale than any previously faced by epidemiologists. Impediments to preserving health through ecological protection are substantial and fundamentally different from previous challenges to public health. Old solutions will not suffice.

For new ecological protection measures to overcome barriers and achieve widespread, sustainable change, one or more of the enablers in Table 32.1 may be required.

\section{Table 32.1 Environmental protection enablers.}

\begin{tabular}{|c|c|}
\hline Enabler & Climate change examples \\
\hline $\begin{array}{l}\text { Substantial ongoing funding to establish } \\
\text { national or international programmes }\end{array}$ & $\begin{array}{l}\text { - Direct national funding of clean energy } \\
\text { infrastructure } \\
\text { - Funding of public transportation systems }\end{array}$ \\
\hline $\begin{array}{l}\text { Regulatory measures that require or facilitate } \\
\text { change in practice }\end{array}$ & $\begin{array}{l}\text { - Government-mandated emission standards } \\
\text { for cars or power plants } \\
\text { - Government-funded industry bailouts linked } \\
\text { to improved environmental practices } \\
\text { - Carbon taxes }\end{array}$ \\
\hline $\begin{array}{l}\text { Market forces that encourage organisations } \\
\text { to change practice }\end{array}$ & $\begin{array}{l}\text { - Boycotts of environmentally unfriendly products } \\
\text { - Clean energy becoming less expensive than } \\
\text { fossil fuel-based energy } \\
\text { - Carbon trading schemes }\end{array}$ \\
\hline $\begin{array}{l}\text { Integration of successful local strategies into } \\
\text { existing national or international networks or } \\
\text { programmes }\end{array}$ & $\begin{array}{l}\text { - A 'health in all policies' approach to governing } \\
\text { that recognises the links between ecological } \\
\text { and human health } \\
\text { - Integration of local energy-efficient building } \\
\text { design principles into all future government- } \\
\text { funded buildings }\end{array}$ \\
\hline
\end{tabular}

Source: Author's work. 
Most countries could afford to engage in substantial and accelerated change in their energy infrastructure (enabler 1), but this has so far been politically unfeasible. They could realistically set up a system of incentives and disincentives, such as implementing carbon taxes and ending oil subsidies (enabler 2), which would nudge energy companies towards more sustainable energy production. Enhancing the influence of epidemiological theory and research in the policy debate that determines such action is therefore necessary, and, indeed, critically important. The participation of developing countries is essential, given their rapidly growing ecological footprints, as is the involvement of developed countries. While such countries want to avoid economic disadvantage, their populations could experience many health co-benefits from a number of mitigation strategies. For instance, green cities planned to facilitate decreased car use would lead to reduced incidence of obesity and cardiovascular disease.

However, it is not just at the policy level where epidemiology has a role. In the context of climate change, substantial increases in access to government policy levers are unlikely without a widespread understanding of the threat that climate change and other ecological health determinants play. Epidemiologically informed education of the general population is therefore critical. This should begin at school, but cannot wait until the next generation attains the vote, and should target adults as well. Such education could serve to alter the salience of distal consequences, and help to increase consumer demand for clean energy. This approach offers particular opportunities for epidemiology because health - consistently rated as a high voting priority in community surveys (Research Australia, 2012) - has not yet been linked strongly to climate change in the public discourse. The public may, therefore, be more responsive to messages that climate change will impact health, and consequently will be more likely to support mitigation and adaptation measures than after exposure to environmental or national security messages (Myers et al., 2012). However, given the five impediments discussed above, no large-scale shift in the market towards clean infrastructure (enabler 3) is likely until its cost approaches that of traditional energy. Government taxes and subsidies, if structured correctly, could force this equality of pricing.

Finally, since the amelioration of climate change requires 'silver buckshot', ecological and epidemiological thinking needs to occur in unfamiliar realms, unaccustomed to such considerations (enabler 4). The concept of 'health in all policies' (Ståhl et al., 2006; Puska, 2007) might be extended to include ecological health, on which human health depends. Incentive creation will be required, both in government and private enterprises unused to thinking in such terms. Another necessary condition for success will be enhancing ecological 
and epidemiological wisdom in these areas. Two parallel strategies are useful: increasing the number of experts and embedding epidemiology and ecology in the core curriculum of the education system, including at universities.

In the 1800s, public health practitioners revolutionised health care by expanding the accepted purview of health specialists to include social and economic determinants of health. Today's global environmental threats to health are qualitatively different in ways that preclude previous solutions. However, an expansion of discipline and its tools similar to that experienced in the 19th century is required. Recently, as Tony McMichael both chronicled and exemplified, epidemiologists have been enhancing their understanding of the importance of ecological stability for human health. It is unsurprising that he had already begun to expand epidemiological action to have some influence over the ecological determinants of health, having provided advice to the Australian Prime Minister and the Chief Scientist. Clearly, much remains to be done. Continuation of his work is vital to the future health of the planet and its inhabitants.

\section{References}

Balas, E.A. \& Boren, S.A. 2000. Managing clinical knowledge for health care improvement. Yearbook of Medical Informatics 2000, 65-70.

Balmford, A., Bruner, A., Cooper, P., Costanza, R., Farber, S., Green, R.E., et al. 2002. Economic reasons for conserving wild nature. Science 297, 950-3.

Barnosky, A.D., Matzke, N., Tomiya, S., Wogan, G.O.U., Swartz, B., Quental, T.B., et al. 2011. Has the Earth's sixth mass extinction already arrived? Nature 471, 51-7.

Bowles, D.C., Braidwood, M. \& Butler, C.D. 2014. Unholy Trinity: climate change, conflict and ill health. In: Butler, C.D. (ed.) Climate Change and Global Health, CABI, Wallingford, UK, 144-52.

Bradbury, R. 2012. A world without coral reefs. New York Times. New York, USA. www.nytimes.com/2012/07/14/opinion/a-world-without-coral-reefs. html?_r=0, accessed 5 July 2015.

Butler, C.D. \& Harley, D. 2010. Primary, secondary and tertiary effects of ecoclimatic change: the medical response. Postgraduate Medical Journal 86, 230-4.

Comaroff, J. \& Comaroff, J.L. 1991. Of Revelation and Revolution. Vol. 1: Christianity, Colonialism, and Consciousness in South Africa. University of Chicago Press, Chicago, Illinois, USA. 
Costello, A., Abbas, M., Allen, A., Ball, S., Bell, S., Bellamy, R., et al. 2009. Managing the health effects of climate change: Lancet and University College London Institute for Global Health Commission. The Lancet 373, 1693-1733.

Cribb, J. 2010. The Coming Famine: The Global Food Crisis and What We Can Do to Avoid It. University of California Press, Berkeley, California, USA.

Crutzen, P.J. 2002. Geology of mankind. Nature 415, 23.

Davidson, E.A., de Araujo, A.C., Artaxo, P., Balch, J.K., Brown, I.F., Bustamante, M.M.C., et al. 2012. The Amazon basin in transition. Nature 481, 321-8.

Diamond, J. 2005. Collapse: How Societies Choose to Fail or Succeed. Viking, New York, USA.

Epstein, P.R. \& Ferber, D. 2011. Changing Planet, Changing Health: How the Climate Crisis Threatens Our Health and What We Can Do About It. University of California Press, Berkeley, California, USA.

Foucault, M. 1980. The History of Sexuality: An Introduction. Vintage Books, New York, USA.

Friedlingstein, P., Solomon, S., Plattner, G., Knutti, R., Ciais, P. \& Raupach, M. 2011. Long-term climate implications of twenty-first century options for carbon dioxide emission mitigation. Nature Climate Change 1, 457-61.

Gardiner, S.M. 2006. A perfect moral storm: climate change, intergenerational ethics and the problem of moral corruption. Environmental Values 15, 397-413.

Graham, I.D., Logan, J., Harrison, M.B., Straus, S.E., Tetroe, J., Caswell, W., et al. 2006. Lost in knowledge translation: time for a map? Journal of Continuing Education in the Health Professions 26, 13-24.

Hamilton, C. 2010. Requiem for a Species: Why We Resist the Truth about Climate Change. Allen \& Unwin, Sydney, New South Wales, Australia.

Hendrix, C.S. \& Salehyan, I. 2012. Climate change, rainfall, and social conflict in Africa. Journal of Peace Research 49, 35-50.

Kubiszewski, I., Costanza, R., Dorji, L., Thoennes, P. \& Tshering, K. 2013. An initial estimate of the value of ecosystem services in Bhutan. Ecosystem Services 3, e11-e22.

McGlynn, E.A., Asch, S.M., Adams, J., Keesey, J., Hicks, J., DeCristofaro, A., et al. 2003. The quality of health care delivered to adults in the United States. New England Journal of Medicine 348, 2635-45. 
McMichael, A.J. 1999. Prisoners of the proximate: loosening the constraints on epidemiology in an age of change. American Journal of Epidemiology 149, 887-97.

McMichael, A.J. 2012. Insights from past millennia into climatic impacts on human health and survival. Proceedings of the National Academy of Sciences (USA). 109, 4730-7.

Mazo, J. 2010. Climate Conflict: How Global Warming Threatens Security and What to Do About It. Routledge, the International Institute for Strategic Studies, London, UK.

Morisetti, N. 2012. Climate change and resource security. BMJ 344, el352.

Myers, T.A., Nisbet, M.C., Maibach, E.W. \& Leiserowitz, A.A. 2012. A public health frame arouses hopeful emotions about climate change. Climatic Change, 113, 1105-12,

Pearse, G. 2007. High \& Dry: John Howard, Climate Change and the Selling of Australia's Future. Viking/Penguin, Camberwell, VIC, Australia.

Puska, P. 2007. Health in all policies. The European Journal of Public Health $17,328$.

Research Australia 2012. What do Australians think about health \& medical research? 2012 opinion poll - views of over 1000 Australians. Research Australia, Sydney, NSW, Australia.

Rockström, J., Steffen, W., Noone, K., Persson, A., Chapin, F.S., Lambin, E.F., et al. 2009. A safe operating space for humanity. Nature 461, 472-5.

Runciman, W.B., Hunt, T.D., Hannaford, N.A., Hibbert, P.D., Westbrook, J.I., Colera, E.W., et al. 2012. CareTrack: assessing the appropriateness of health care delivery in Australia. Medical Journal of Australia 197, 100-5.

Ståhl, T., Wismar, M., Ollila, E., Lahtinen, E. \& Leppo, K. 2006. Health in all Policies. Prospects and Potentials. Finnish Ministry of Social Affairs and Health, Helsinki, Finland.

Steffen, W., Grinevald, J., Crutzen, P. \& McNeill, J. 2011. The Anthropocene: conceptual and historical perspectives. Philosophical Transactions of the Royal Society A: Mathematical, Physical and Engineering Sciences 369, 842-67.

Sullivan, G.R., Bowman, F., Ferrell, L.P.J., Gaffney, P.G.I., Kern, P.J., Lopez, T.J., et al. 2007. National Security and the Threat of Climate Change. The Center for Naval Analysis (CAN) Corporation, Alexandria, Virginia, USA. 
Zhang, D.D., Brecke, P., Lee, H.F., He, Y.-Q. \& Zhang, J. 2007. Global climate change, war, and population decline in recent human history. Proceedings of the National Academy of Sciences (USA) 104, 19214-9.

Zhang, D.D., Lee, H.F., Wang, C., Li, B., Pei, Q., Zhang, J., et al. 2011. The causality analysis of climate change and large-scale human crisis. Proceedings of the National Academy of Sciences (USA) 108, 17296-301. 
This text is taken from Health of People, Places And Planet:

Reflections based on Tony McMichael's four decades of contribution to epidemiological understanding, edited by Colin D. Butler, Jane Dixon and Anthony G. Capon, published 2015 by ANU Press, The Australian National University, Canberra, Australia. 